\title{
Investigating the role of CD44 and hyaluronate in embryo- epithelial interaction using an in-vitro model
}

DOI:

10.1093/molehr/gaz011

\section{Document Version}

Accepted author manuscript

Link to publication record in Manchester Research Explorer

\section{Citation for published version (APA):}

Berneau, S., Ruane, P., Brison, D. R., Kimber, S., Westwood, M., \& Aplin, J. (2019). Investigating the role of CD44 and hyaluronate in embryo-epithelial interaction using an in-vitro model. Molecular Human Reproduction. https://doi.org/10.1093/molehr/gaz011

\section{Published in:}

Molecular Human Reproduction

\section{Citing this paper}

Please note that where the full-text provided on Manchester Research Explorer is the Author Accepted Manuscript or Proof version this may differ from the final Published version. If citing, it is advised that you check and use the publisher's definitive version.

\section{General rights}

Copyright and moral rights for the publications made accessible in the Research Explorer are retained by the authors and/or other copyright owners and it is a condition of accessing publications that users recognise and abide by the legal requirements associated with these rights.

\section{Takedown policy}

If you believe that this document breaches copyright please refer to the University of Manchester's Takedown Procedures [http://man.ac.uk/04Y6Bo] or contact uml.scholarlycommunications@manchester.ac.uk providing relevant details, so we can investigate your claim.

\section{OPEN ACCESS}


1 Investigating the role of CD44 and hyaluronate in embryo-epithelial interaction

2 using an in-vitro model

3 Berneau SC ${ }^{1}$, Ruane $\mathrm{PT}^{1}$, Brison $\mathrm{DR}^{1,2}$, Kimber SJ ${ }^{3}$, Westwood $\mathrm{M}^{1}$, Aplin JD ${ }^{1}$

$4{ }^{1}$ Maternal and Fetal Health Centre and Division of Developmental Biology and 5 Medicine, Faculty of Biology, Medicine and Health, University of Manchester, 6 Manchester Academic Health Sciences Centre, St Mary's Hospital, Manchester M13 7 9WL, UK

$8{ }^{2}$ Department of Reproductive Medicine, Old St Mary's Hospital, Central Manchester 9 University Hospitals NHS Foundation Trust, Manchester Academic Health Science 10 Centre, Oxford Road, Manchester M13 9WL, UK.

$11{ }^{3}$ Division of Cell Matrix Biology and Regenerative Medicine, School of Biological

12 Sciences, Faculty of Biology Medicine and Health, University of Manchester, Michael

13 Smith Building, Manchester M13 9PT, UK.

14 Running title: CD44 - hyaluronate interaction at implantation 


\section{Abstract}

22 Implantation failure is an important impediment to increasing success rates in assisted 23 reproductive technologies (ART). Knowledge of the cascade of morphological and 24 molecular events at implantation remains limited. Cell surface CD44 and hyaluronate $25(\mathrm{HA})$ have been reported in the uterus, but a role in intercellular interaction at 26 implantation remains to be evaluated. Mouse embryos were co-cultured with human 27 Ishikawa endometrial epithelial monolayers over two days. Attachment was tenuous 28 during the first $24 \mathrm{hrs}$, after which it became stable, leading to breaching of the 29 monolayer. The effects of enzymatically reducing the density of $\mathrm{HA}$, or introducing a 30 function-blocking antibody to CD44, were monitored during progression from weak to

31 stable embryonic attachment. Hyaluronidase-mediated removal of surface HA from the 32 epithelial cells enhanced the speed of attachment, while a similar treatment of 33 embryos had no effect. The antibody to CD44 caused retardation of initial attachment.

34 These results suggest that CD44-HA binding could be employed by embryos during 35 initial docking, but the persistence of HA in epithelial cells might be detrimental to later 36 stages of implantation by retarding attainment of stable attachment.

37 Keywords: CD44, hyaluronate, implantation, endometrium, embryo adhesion.

\section{Introduction}

$39 \mathrm{CD} 44$ is a cell surface glycoprotein that acts as a receptor for hyaluronan (HA) as well 40 as other ligands including osteopontin (OPN), collagens and matrix metalloproteinase 419 (Misra et al., 2015, Senbanjo and Chellaiah, 2017). CD44 is present in a wide range 42 of cells, with a complex pattern of splice variants and glycoforms, including the 43 trophectoderm of both human and mouse blastocysts (Campbell et al., 1995, Lu et al., 44 2002) and endometrial tissue. In the mid secretory phase, when embryo implantation 
45

46

47

48

49

50

51

52

53 ligand sensitive to glycoform has not been identified.

$54 \mathrm{HA}$ is present in uterine fluid and on the surface of the endometrial epithelium

55 (Fouladi-Nashta et al., 2017). Treatment of mouse embryos with HA promoted 56 implantation (Gardner et al., 1999), and HA-containing embryo transfer medium used 57 in ART has been reported to improve implantation and increase live birth rates in 58 humans (Bontekoe et al., 2014). CD44-HA interactions have therefore been implicated 59 in embryo attachment during the early stages of implantation. HA is proposed to bridge 60 between embryo and endometrial epithelium through CD44 (and possibly other 61 receptors), while OPN dimers (Goldsmith et al., 2002) may bridge CD44 and/or integrin $62 \alpha v \beta 3$. OPN is a strong candidate adhesion molecule for implantation (Johnson et al.,

$632014)$ and we have previously shown that integrin $\alpha v \beta 3-O P N$ interactions contribute to 64 embryo attachment to epithelium in vitro (Kang et al., 2014). Recent experimental 65 manipulation of HA in the sheep uterus however suggests that endometrial HA may act 66 to inhibit implantation (Fouladi-Nashta et al., 2017, Marei et al., 2017).

67 We have used Ishikawa cells as a model endometrial epithelium for examining 68 interaction with blastocyst stage embryos (Ruane et al., 2017, Ruane et al., 2018, 
69 Singh et al., 2010). When embryos are transferred to confluent Ishikawa cell 70 monolayers, initial attachment to the apical surface is followed by breaching and 71 trophoblast outgrowth. A proteomic profile of glycoproteins exposed at the apical

72 surface of confluent, polarised Ishikawa cells included CD44 (Aplin and Ruane, 2017,

73 Singh and Aplin, 2015, Singh et al., 2010), verifying that these cells are suitable for 74 evaluating its biological activity in this context. Here we examine the effects of blocking 75 CD44 as well as stripping cell surface HA on attachment of mouse embryos.

\section{Materials and Methods}

\section{Cell culture}

78 Ishikawa cells (ECACC 99040201) were maintained at $37^{\circ} \mathrm{C}, 95 \%$ air and $5 \% \mathrm{CO} 2$ in 79 DMEM (Sigma) containing 10\% fetal bovine serum (Sigma), 2mM L-glutamine, $80100 \mu \mathrm{g} / \mathrm{ml}$ streptomycin and $100 \mathrm{IU} / \mathrm{ml}$ penicillin (Sigma). Cells were grown on $2 \%$ 81 Matrigel-coated $13 \mathrm{~mm}$ glass coverslips (Sigma) in 24-well plates (Corning) up to 82 passage 25.

\section{Mouse embryos}

84 Experiments were carried out under UK Home Office project license PPL 70/07838, and authorised by the Animal Welfare and Ethical Review Board of the University of Manchester, according to the Animal Act, 1986. Eight-week-old CD1 female mice

87 (Charles River) were superovulated (by intraperitoneal injection of 5 IU pregnant 88 mare serum gonadotrophin (Intervet), followed by 5 IU human chorionic 89 gonadotrophin (Intervet) $46 \mathrm{hrs}$ later) and time-mated. The 2-cell embryos were 90 flushed from the oviduct at E (embryo day) 1.5. Embryos were cultured in KSOM 91 medium (Millipore) containing $0.4 \%$ BSA (Sigma) under oil (Vitrolife) to E4.5 then 
92 artificially hatched from the zona pellucidae using acid Tyrode's solution $(\mathrm{pH} 2.5)$ 93 (Sigma).

94 Cell spreading assay

95 Flat-bottom 48-well plates (Corning) were left uncoated or coated overnight with $965 \mu \mathrm{g} / \mathrm{ml}$ osteopontin (R\&D Systems), bovine serum albumin (BSA, Sigma) or poly97 L-lysine (Sigma). Wells were then exposed to a solution of $1 \mathrm{mg} / \mathrm{ml}$ heat-denatured 98 BSA (Sigma) for $1 \mathrm{hr}$. Endometrial cells were trypsinised and incubated with various 99 concentrations of antibody (H-300-L rabbit anti-CD44 (Santa Cruz) or IgG from rabbit 100 serum as negative control, (Sigma); 5,10 or $20 \mu \mathrm{g} / \mathrm{ml}$ in serum-free medium (Teramoto 101 et al., 2005) for $5 \mathrm{~min}$ at room temperature then plated into wells at 2000 cells/well. 102 Cells were cultured for $1 \mathrm{hr}$ then imaged using phase contrast microscopy and 103 analysed using ImageJ.

104 In-vitro attachment assay

105 Confluent endometrial cells were incubated in serum-free medium (DMEM, 2mM $106 \mathrm{~L}$-glutamine, $100 \mu \mathrm{g} / \mathrm{ml}$ streptomycin and $100 \mathrm{IU} / \mathrm{ml}$ penicillin) for $24 \mathrm{hrs}$ prior to 107 co-culture with hatched E4.5 mouse blastocysts (3 per well), as previously described 108 (Ruane et al., 2017).

109 In some experiments, medium was spiked with antibody (H-300-L rabbit anti-CD44 or

$110 \mathrm{IgG}$ from rabbit serum) at $20 \mu \mathrm{g} / \mathrm{ml}$ (determined by data from the cell spreading 111 inhibition assay), either just prior to addition of E4.5 embryos or $24 \mathrm{hrs}$ later just prior to 112 detachment of E5.5 embryos, by gently flushing with $60 \mu$ medium. Mouse embryos 113 flushed at day 4.5 require 28 hrs of incubation with cells to activate them for stable 114 attachment; flushing restored all embryos to an unattached state at the start of the 
115 antibody incubation period. Other experiments involved pre-treatment of embryos and /

116 or Ishikawa cells with hyaluronidase prior to co-culture. Here hatched E4.5 blastocysts

117 were cultured in $\mathrm{KSOM}, 0.4 \% \mathrm{BSA}$ to E5.5, then incubated with, or without, $500 \mathrm{IU} / \mathrm{ml}$

118 hyaluronidase (Sigma) in KSOM, 0.4\% BSA for 30 minutes before transfer onto treated

119 or untreated cells. Ishikawa cells were treated by culturing as usual for $24 \mathrm{hrs,}$

120 removing and retaining the conditioned medium during a 30 min incubation with 500

$121 \mathrm{IU} / \mathrm{ml}$ hyaluronidase (in fresh serum-free culture medium), then replacing the retained

122 medium before adding treated or untreated E5.5 embryos.

123 In all experiments, attachment stability was assessed as previously described (Ruane

124 et al., 2017), every 4 hrs during the first $12 \mathrm{hrs}$ of co-culture then at 24, 28, $32,36 \mathrm{hrs}$

125 and finally at 48 hrs (E6.5 of mouse embryo development) using an inverted phase

126 contrast microscope (Evos XL Core). Co-cultures were then fixed with 4\% PFA for 20

$127 \mathrm{~min}$ at room temperature and stored under PBS at $4^{\circ} \mathrm{C}$.

128 Single embryo fluorescence staining

129 Hatched E4.5 embryos were fixed in a staining solution (3\% BSA in PBS) containing $1301 \%$ PFA for $20 \mathrm{~min}$, quenched in $50 \mathrm{mM}$ ammonium chloride for $5 \mathrm{~min}$, then 131 permeabilised using $0.5 \%$ Triton-X100 PBS solution for 6 min. Blastocysts were 132 incubated overnight at $4^{\circ} \mathrm{C}$ in a $25 \mu \mathrm{l}$ drop of staining solution containing $\mathrm{H}-300-\mathrm{L}$ rabbit 133 anti-CD44 or IgG from rabbit serum under mineral oil (Sigma) followed by staining 134 solution containing an Alexa Fluor 488-labelled secondary antibody (Life 135 Technologies) and 4',6-diamidino-2-phenylindole (DAPI, Sigma) for $1 \mathrm{hr}$. Embryos 136 were mounted in a poly-L lysine-coated chamber of 3\% 1,4-diazabicyclo[2.2.2]octane 137 (DABCO, Sigma) in PBS. 
139 PFA-fixed cells and co-cultures were quenched with $50 \mathrm{mM}$ ammonium chloride before 140 permeabilisation in $0.5 \%$ Triton-X100 PBS. Mouse monoclonal anti-CD44 antibody 141 (5F12, NeoMarkers Fremont) and IgG from mouse serum (negative control, Sigma) 142 and Alexa Fluor 488-labelled secondary antibody (Life Technologies) were used to

143 stain Ishikawa cells and attachment sites. Rabbit polyclonal (H-300-L, Santa Cruz) was

144 used in some experiments. Hyaluronan was visualised by incubating samples for $3 \mathrm{hrs}$ 145 at room temperature with a biotinylated hyaluronan binding protein (Biotin-HABP, 146 Amsbio), followed by streptavidin-fluorescein isothiocyanate for $1 \mathrm{hr}$ at room 147 temperature. Nuclear and actin stains were performed using a mixture of DAPI (Sigma) 148 and Alexa Fluor® 568-coupled Phalloidin (Invitrogen). Coverslips with cell layers were 149 mounted upside down on a microscope slide in a drop of Mowiol 4-88 mounting 150 medium (Sigma) containing 3\% DABCO. Coverslips with embryo-Ishikawa cells were 151 mounted a chamber of $3 \%$ DABCO in PBS to maintain the 3D structure of the 152 attachment sites.

\section{Fluorescence microscopy}

154 Fluorescence microscopy images were taken with an inverted Zeiss microscope, Zen 1552.0 software and the Apotome 2 module, and analysed with ImageJ. Z-series optical 156 sections of cells were obtained at the minimum of $0.24 \mu \mathrm{m}$ increments for $40 \mathrm{X}$ and $63 \mathrm{X}$ 157 objectives. Z-stacks of embryo and embryo attachment sites were obtained at 1-2 $\mu \mathrm{m}$ 158 increments at $40 \mathrm{X}$ for a maximal distance of $60 \mu \mathrm{m}$.

159 Statistics

160 Data generated from embryo attachment assays and cell spreading assays are 161 represented as mean \pm the standard error of the mean or median and interquartile 162 range. Statistical analysis using Prism software (Graph-Pad, USA) included the 2-way 
163 ANOVA test followed by Bonferroni's multiple comparisons post-hoc test or non-

164 parametric Wilcoxon, Mann-Whitney \& Friedman tests.

\section{Results}

CD44 immunoreactivity in blastocysts and Ishikawa cells

167 The rabbit polyclonal antibody H300 against CD44 showed heterogeneous binding in 168 the trophectoderm of chemically hatched mouse blastocysts (Figure 1A-C). As 169 previously reported (Behzad et al., 1994, Singh et al., 2010), Ishikawa cells express 170 CD44. The monoclonal antibody 5F12, which did not show any reactivity with mouse

171 embryos, revealed linear lateral distribution of immunoreactivity as well as more diffuse 172 punctate staining in Ishikawa cells, with considerable intercellular variation (Figure 1D).

173 Heterogeneous immunoreactivity was in ruffles at the apical surface (Figure 1E).

174 Variation of culture conditions, including the presence and absence of serum and/or 175 matrigel as a substrate, did not cause significant changes (not shown).

\section{CD44 immunoreactivity in attachment sites in vitro}

177 Transfer of hatched E4.5 mouse blastocysts to Ishikawa epithelial cell monolayers is

178 followed by an initial period ( $28 \mathrm{hrs}$ ) of weak and reversible attachment that initiates

179 the activation required for embryos to progress, over the next $20 \mathrm{hrs,} \mathrm{from} \mathrm{stable}$ 180 attachment to breaching and displacement of the underlying cells (Ruane et al., 2017).

181 Figure $2 \mathrm{~A}$ shows $5 \mathrm{~F} 12$ reactivity in cells surrounding an attachment site with no 182 trophoblast invasion, whereas in Figure $2 \mathrm{~B}$, the trophoblast has breached the 183 subjacent cell layer and is beginning to laterally invade, with CD44-positive epithelial 184 cells crowded together in adjacent locations. Figure $2 \mathrm{C}$ surveys a subsequent stage in 185 which trophoblast giant cells with prominent stress fibres are apparent spreading over 
186 the substrate. Intensity scans of such sites showed no significant change in CD44

187 immunoreactivity in cells adjacent to the embryo either at this or earlier pre-breaching 188 stages of attachment (not shown). Note this antibody does not detect staining in cells 189 in adherent embryos.

190 Function-blocking antibody to CD44 can delay attachment

191 To test the hypothesis that CD44 might mediate attachment of blastocysts to epithelial 192 cell layers, a function-blocking antibody, H300, was introduced into co-cultures. HA 193 does not bind to culture plastic, so the potency of H300 as an inhibitor of CD44 194 function in Ishikawa cells was examined using an adhesion assay which monitors the 195 capacity of cells to spread on dishes coated with OPN (Figure 3A,B). Inclusion of H300 196 resulted in partial inhibition ( 55\%) of spreading when cells were plated on OPN but 197 the antibody had no effect when a control substrate containing poly-L-lysine was used.

198 Alterations to embryo behaviour in response to antibody inhibition of CD44 function 199 were evaluated using a stability scale in which unattached and weakly attached 200 embryos can be reliably distinguished from those achieving intermediate or fully stable 201 attachment (Ruane et al., 2017). Unattached embryos move across the monolayer 202 when disturbed, while weakly and intermediately attached embryos are identifiable by 203 high and low levels of oscillation, respectively, about an attachment point. Stably 204 attached embryos do not oscillate. Combining intermediate and stable attachment 205 scores produces a measure of irreversible attachment (Ruane et al., 2017).

206 Introducing antibody to cultures just prior to the addition of E4.5 embryos impacted on 207 weak attachment in the first $8 \mathrm{hrs}$, and inhibited the level of stable attachment levels at 20832 hrs co-culture (Figure $3 C, D$ ). In a second series of experiments, the antibody was 209 added after $24 \mathrm{hrs}$ co-culture when embryos were at E5.5 and beginning to advance 
210 from weak to stable attachment. Weakly adherent embryos were mechanically

211 detached at the time of antibody addition, which we have previously demonstrated 212 does not impact on their ability to progress to stable attachment (Ruane et al., 2017).

213 Antibody spiking at this time point reduced total attachment levels between 28 and 32 214 hrs, though by 36 hrs the treated embryos had caught up with controls. Moreover, a 215 trend towards reduced stable attachment was observed from 28-36 hrs with significant 216 inhibition of stable attachment at $36 \mathrm{hrs}$ (Figure 3E,F).

\section{A role for endometrial hyaluronan in early embryo attachment}

218 A fluorescent conjugate of the HA-binding domain of versican applied to fixed Ishikawa 219 cells revealed prominent fluorescence, demonstrating HA localisation at the apical 220 surface, where embryos initially dock (Figure 4A). After treatment with the enzyme 221 Hyal2, which cleaves high molecular mass HA into smaller fragments, cells showed a 222 negligible level of fluorescence (Figure 4B,C). There was no change in CD44 223 distribution in the treated cells (Figure 4D,E).

224 We then went on to investigate whether this apical surface-localised HA might 225 contribute to the attachment reaction. We carried out co-cultures from E5.5, using cells 226 and/or embryos pre-treated with Hyal2. Embryos stably attached more rapidly to cells 227 that had been treated with the enzyme, the difference being apparent between 28 and $22832 \mathrm{hrs}$; by $48 \mathrm{hrs}$ the embryos had attached as stably as in untreated controls (Figure 229 4F,G). Comparing total attachment levels with those of stable attachment 230 demonstrated that loss of HA has little effect on weak attachment at this embryonic 231 stage (Figure 4F,G). Treating embryos with Hyal2 had no effect on attachment kinetics 232 (Figure 4F,G).

\section{Discussion}


234 Our model system allows a detailed analysis of the kinetics of embryo attachment, 235 which progresses from a reversible weak stage, with activation of trophoblast gene 236 expression, to an irreversible stable stage that rapidly progresses to epithelial 237 breaching (Kang et al., 2014, Ruane et al., 2017). CD44 immunoreactivity in Ishikawa 238 cells and blastocysts is consistent with our previously reported analysis of the apical 239 Ishikawa glycoproteome (Singh and Aplin, 2015) and matches CD44 localisation in 240 human and murine blastocysts (Campbell et al., 1995; Lu et al., 2002). Data herein 241 reveal that the presence of a function-blocking CD44 antibody leads to a delay in the 242 progression of embryos to a stably attached state. Additionally, we found that 243 enzymatic degradation of the CD44 ligand HA from the apical surface of Ishikawa cell 244 layers, but not the blastocyst, hastened the attainment of stable attachment, with 245 minimal effects on weak attachment. Together these data suggest that CD44 246 contributes to weak embryo attachment in a HA-independent manner while 247 endometrial HA acts as a brake on progression to stable attachment.

248 Reflecting these data, pharmacological inhibition of uterine HA synthesis in sheep 249 leads to its disappearance from the uterine apical epithelial surface and a 250 corresponding increase in embryo attachment. Conversely, infusion of HA into the 251 lumen inhibits implantation (Marei et al., 2017). HA may therefore act analogously to 252 the functions of mucins MUC1 and MUC16 (Aplin, 2000, Dharmaraj et al., 2014, 253 Gipson et al., 2008, Hey et al., 1994, Meseguer et al., 2001). Moreover, embryonic 254 activity causing loss of HA from the epithelial surface, as seen for MUC1 (Meseguer et 255 al., 2001, Singh et al., 2010), may underlie the progression to stable attachment.

256 The use of $\mathrm{HA}$ as a supplement at the time of embryo transfer has received 257 considerable attention in ART (Fouladi-Nashta et al., 2017, Singh et al., 2015), and 
258 there is evidence to suggest that exogenous HA can bind to the luminal apical 259 epithelial cell membrane (Marei et al., 2017). Supplementation would be justified only if 260 HA can be demonstrated to have a role in improving embryo viability, acquisition of 261 blastocyst adhesion competence or supporting development that precedes the 262 interaction with maternal epithelium at the start of implantation. Embryo development 263 and viability were found to be improved after culture in HA-supplemented media in 264 humans (Simon et al., 2003) and in other animal models (Gardner et al., 1999, Romek 265 et al., 2017, Lane et al., 2003). Exogenous HA may actually delay rather than promote 266 implantation in humans, and this impact on timing could underlie the beneficial effects 267 of such transfer medium by allowing acclimatisation of the blastocyst to the uterine 268 environment before implantation, or indeed synchronising a delayed window of 269 receptivity with the implantation-ready blastocyst. HA-enriched transfer medium has 270 also been shown to be beneficial during cleavage-stage embryo transfer (Urman et al., 271 2008; Nakagawa et al., 2012), implying that exogenous HA impacts upon embryo 272 development or the acquisition of a receptive endometrium. However, the beneficial 273 effect of HA-supplementation embryo transfer medium on implantation rate and clinical 274 pregnancy is controversial (Simon et al., 2003, Fancsovits et al., 2015).

275 The presence of CD44 at the blastocyst-uterine interface is not essential for 276 implantation in mice: CD44 null mice are fertile and viable with no morphological defect 277 (Schmits et al., 1997, Protin et al., 1999). In these studies, CD44 null offspring from 278 heterozygotic matings followed Mendelian rules, and their fertility status was reported, 279 though not shown, based on breeding of the $F_{1}$ generation. Another HA-binding 280 receptor, RHAMM, is expressed both in blastocysts (Choudhary et al., 2009) and 281 endometrium (Rein et al., 2003, Ozbilgin et al., 2012), and could potentially 282 compensate for the absence of CD44 (Nedvetzki et al., 2004, Naor et al., 2007, Toole, 
283 2009), but it has not been investigated in CD44-null animals. Further investigations are 284 necessary to determine the role of RHAMM in embryo attachment at implantation.

285 The anti-CD44 antibody we used has been shown to block binding of OPN to the N286 terminus (Teramoto et al., 2005). Since this is also the major binding site in CD44 for $287 \mathrm{HA}$, the antibody is likely to impair HA binding (Banerji et al., 2007, Peach et al., 1993). 288 In the cell spreading assay, targeting CD44 was not expected to achieve a full 289 inhibition as the endometrial cells express integrins also known to interact with OPN 290 (Kang et al., 2014). Furthermore, our HA clearance data suggest endogenous OPN is 291 the more likely ligand involved in CD44-mediated early attachment between 292 trophectoderm and endometrial epithelial cells (Kang et al., 2014). This study provides 293 evidence of a role for the CD44-OPN-HA axis in timely progression from weak 294 (CD44-OPN) to stable (loss of HA) attachment, which we believe is important for the 295 development of the invasive trophoblast required for the establishment of pregnancy 296 (Ruane et al., 2017). If the observations were to translate to human embryos 297 implanting in vivo, a delay of a few hours towards the end of the receptive phase might 298 lead to failure to rescue the corpus luteum, and subsequent loss of the pregnancy 299 (Baird et al., 1991). Conversely, rapid stable attachment caused by reduced HA could 300 allow the implantation of developmentally incompetent embryos with the potential to 301 miscarry (Aplin et al., 1996, Quenby et al., 2002, Teklenburg et al., 2010).

302 In conclusion, our study demonstrates for the first time the role of CD44 at the early 303 stages of embryo-uterine attachment using an in-vitro implantation model and sets the 304 scene for further investigations to determine the role of other HA-receptors and CD44 305 ligands at implantation. 
307 S.C.B., S.J.K., M.W. and J.D.A. designed the study, and S.J.K., D.R.B., M.W. and J.D.A. 308 obtained funding. S.C.B. carried out the experimental work. J.D.A., S.C.B. and P.T.R. 309 wrote the paper, which was edited by S.J.K., D.R.B. and M.W.

\section{Funding}

311 This work was supported by funds from the charity Diabetes UK (15/0005207) and 312 studentship support for S.C.B. from the Anatomical Society.

\section{Conflict of interest}

314 None declared

\section{References}

316 Afify AM, Craig S, Paulino AF. Temporal variation in the distribution of hyaluronic acid, 317 CD44s, and CD44v6 in the human endometrium across the menstrual cycle. Appl 318 Immunohistochem Mol Morphol 2006;14:328-333.

319 Albers A, Thie M, Hohn HP, Denker HW. Differential expression and localization of 320 integrins and CD44 in the membrane domains of human uterine epithelial cells during 321 the menstrual cycle. Acta Anat (Basel) 1995;153:12-19.

322 Aplin JD. The cell biological basis of human implantation. Baillieres Best Pract Res 323 Clin Obstet Gynaecol 2000;14:757-764. Aplin JD. The cell biological basis of human 324 implantation. Baillieres Best Pract Res Clin Obstet Gynaecol 2000;14:757-764.

325 Aplin JD, Hey NA, Li TC. MUC1 as a cell surface and secretory component of 326 endometrial epithelium: reduced levels in recurrent miscarriage. Am $J$ Reprod 327 Immunol 1996;35:261-266. 
328 Aplin JD, Ruane PT. Embryo-epithelium interactions during implantation at a glance. $J$ 329 Cell Sci 2017;130:15-22.

330 Baird DD, Weinberg CR, Wilcox AJ, McConnaughey DR, Musey PI, Collins DC. 331 Hormonal profiles of natural conception cycles ending in early, unrecognized 332 pregnancy loss. J Clin Endocrinol Metab 1991;72:793-800.

333 Banerji S, Wright AJ, Noble M, Mahoney DJ, Campbell ID, Day AJ, Jackson DG. 334 Structures of the Cd44-hyaluronan complex provide insight into a fundamental 335 carbohydrate-protein interaction. Nat Struct Mol Biol 2007;14:234-239.

336 Behzad F, Seif MW, Campbell S, Aplin JD. Expression of two isoforms of CD44 in 337 human endometrium. Biol Reprod 1994;51:739-747.

338 Bontekoe S, Heineman MJ, Johnson N, Blake D. Adherence compounds in embryo 339 transfer media for assisted reproductive technologies. Cochrane Database Syst Rev $340 \quad$ 2014;2:CD007421.

341 Campbell S, Swann HR, Aplin JD, Seif MW, Kimber SJ, Elstein M. CD44 is expressed 342 throughout pre-implantation human embryo development. Hum Reprod 1995;10:425343430.

344 Choudhary M, Zhang X, Stojkovic P, Hyslop L,Anyfantis G, Herbert M, Murdoch AP, 345 Stojkovic M, Lako M. Putative role of hyaluronan and its related genes, HAS2 and 346 RHAMM, in human early preimplantation embryogenesis and embryonic stem cell 347 characterization. Stem Cells 2007;25:3045-57. 
348 Dharmaraj N, Chapela PJ, Morgado M, Hawkins SM, Lessey BA, Young SL, Carson 349 DD. Expression of the transmembrane mucins, MUC1, MUC4 and MUC16, in normal 350 endometrium and in endometriosis. Hum Reprod 2014;29:1730-1738.

351 Fancsovits P, Lehner A, Murber A, Kaszas Z, Rigo J, Urbancsek J. Effect of 352 hyaluronan-enriched embryo transfer medium on IVF outcome: a prospective 353 randomized clinical trial. Arch Gynecol Obstet 2015;291:1173-9.

354 Fouladi-Nashta AA, Raheem KA, Marei WF, Ghafari F, Hartshorne GM. Regulation 355 and roles of the hyaluronan system in mammalian reproduction. Reproduction 356 2017;153:R43-R58.

357 Fujita N, Yaegashi N, Ide Y, Sato S, Nakamura M, Ishiwata I, Yajima A. Expression of 358 CD44 in normal human versus tumor endometrial tissues: possible implication of 359 reduced expression of CD44 in lymph-vascular space involvement of cancer cells. 360 Cancer Res 1994;54:3922-3928.

361 Gardner DK, Rodriegez-Martinez H, Lane M. Fetal development after transfer is 362 increased by replacing protein with the glycosaminoglycan hyaluronan for mouse 363 embryo culture and transfer. Hum Reprod 1999;14:2575-80.

364 Gipson IK, Blalock T, Tisdale A, Spurr-Michaud S, Allcorn S, Stavreus-Evers A, 365 Gemzell K. MUC16 is lost from the uterodome (pinopode) surface of the receptive 366 human endometrium: in vitro evidence that MUC16 is a barrier to trophoblast 367 adherence. Biol Reprod 2008;78:134-142.

368 Griffith JS, Liu YG, Tekmal RR, Binkley PA, Holden AE, Schenken RS. Menstrual 369 endometrial cells from women with endometriosis demonstrate increased adherence 
370 to peritoneal cells and increased expression of CD44 splice variants. Fertil Steril $3712010 ; 93: 1745-1749$.

372 Goldsmith HL, Labrosse JM, McIntosh FA, Mäenpää PH, Kaartinen MT, McKee MD. 373 Homotypic interactions of soluble and immobilized osteopontin. Ann Biomed Eng $374 \quad 2002 ; 30: 840-50$.

375 Hey NA, Graham RA, Seif MW, Aplin JD. The polymorphic epithelial mucin MUC1 in 376 human endometrium is regulated with maximal expression in the implantation phase. 377 J Clin Endocrinol Metab 1994;78:337-342.

378 Johnson GA, Burghardt RC, Bazer FW. Osteopontin: a leading candidate adhesion 379 molecule for implantation in pigs and sheep. J Anim Sci Biotechnol 2014;5:56.

380 Kang YJ, Forbes K, Carver J, Aplin JD. The role of the osteopontin-integrin 381 alphavbeta3 interaction at implantation: functional analysis using three different in vitro 382 models. Hum Reprod 2014;29:739-749.

383 Lane M, Maybach JM, Hooper K, Hasler JF, Gardner DK. Cryo-survival and 384 development of bovine blastocysts are enhanced by culture with recombinant albumin 385 and hyaluronan. Mol Reprod Dev 2003;64:70-78.

386 Lu DP, Tian L, O'Neill C, King NJ. Regulation of cellular adhesion molecule 387 expression in murine oocytes, peri-implantation and post-implantation embryos. Cell 388 Res 2002;12:373-383.

389 Marei WFA, Wathes DC, Raheem KA, Mohey-Elsaeed O, Ghafari F, Fouladi-Nashta 390 AA. Influence of hyaluronan on endometrial receptivity and embryo attachment in 391 sheep. Reprod Fertil Dev 2017;29:1763-1773. 
392 Meseguer M, Aplin JD, Caballero-Campo P, O'Connor JE, Martin JC, Remohi J, 393 Pellicer A, Simon C. Human endometrial mucin MUC1 is up-regulated by 394 progesterone and down-regulated in vitro by the human blastocyst. Biol Reprod $395 \quad 2001 ; 64: 590-601$.

396 Misra S, Hascall VC, Markwald RR, Ghatak S. Interactions between Hyaluronan and 397 Its Receptors (CD44, RHAMM) Regulate the Activities of Inflammation and Cancer. 398 Front Immunol 2015;6:201.

399 Mohamed OA, Jonnaert M, Labelle-Dumais C, Kuroda K, Clarke HJ, Dufort D. Uterine $400 \mathrm{Wnt} /$ beta-catenin signaling is required for implantation. Proc Natl Acad Sci U S A $401 \quad 2005 ; 102: 8579-8584$.

402 Nakagawa K, Takahashi C, Nishi Y, Jyuen H, Sugiyama R, Kuribayashi Y, Sugiyama 403 R. Hyaluronan-enriched transfer medium improves outcome in patients with multiple 404 embryo transfer failures. J Assist Reprod Genet 2002;29:679-85.

405 Noar D, Nedvetszki S, Walmsley M, Yayon A, Turley EA, Golan I, Caspi D, Sebban 406 LE, Zicky Y, Garin T et al. CD44 involvement in autoimmune inflammations: the 407 lesson to be learned from CD44-targeting by antibody or from knockout mice. Ann N Y 408 Acad Sci 2007;1110:233-47.

409 Nedvetzki S, Gonen E, Assayag N, Reich R, Williams RO, Thurmond RL, Huang JF, 410 Neudecker BA, Wang FS, Turley EA et al. RHAMM, a receptor for hyaluronan411 mediated motility, compensates for CD44 in inflamed CD44-knockout mice: a different 412 interpretation of redundancy. Proc Natl Acad Sci U S A 2004;101:18081-18086. 
413 Ozbilgin K, Boz B, Tuğyan K, Inan S, Vatansever S. RHAMM expression in the rat 414 endometrium during the estrous cycle and following implantation. J Reprod Infertil $415 \quad 2012 ; 13: 131-7$.

416 Peach RJ, Hollenbaugh D, Stamenkovic I, Aruffo A. Identification of hyaluronic acid 417 binding sites in the extracellular domain of CD44. J Cell Biol 1993;122:257-264.

418 Protin U, Schweighoffer T, Jochum W, Hilberg F. CD44-deficient mice develop 419 normally with changes in subpopulations and recirculation of lymphocyte subsets. $J$ 420 Immunol 1999;163:4917-23.

421 Quenby S, Vince G, Farquharson R, Aplin J. Recurrent miscarriage: a defect in 422 nature's quality control? Hum Reprod 2002;17:1959-1963.

423 Rein DT, Roehrig K, Schöndorf T, Lazar A, Fleisch M, Niederacher D, Bender HG, 424 Dall P. Expression of the hyaluronan receptor RHAMM in endometrial carcinomas 425 suggests a role in tumour progression and metastasis. J Cancer Res Clin Oncol 426 2003;129:161-4.

427 Romek M, Gajba B, Krzysztofowicz E, Kucia M, Uzarowska A, Smorag Z. Improved 428 quality of porcine embryos cultured with hyaluronan due to the modification of the 429 mitochondrial membrane potential and reactive oxygen species level. Theriogenology $430 \quad 2017 ; 102: 1-9$.

431 Ruane PT, Berneau SC, Koeck R, Watts J, Kimber SJ, Brison DR, Westwood M, Aplin 432 JD. Apposition to endometrial epithelial cells activates mouse blastocysts for 433 implantation. Mol Hum Reprod 2017;23:617-627. 
434 Ruane PT, Koeck R, Berneau SC, Kimber SJ, Westwood M, Brison DR, Aplin JD.

435 Osmotic stress induces JNK-dependent embryo invasion in a model of implantation. 436 Reproduction 2018;156:421-428.

437 Saegusa M, Hashimura M, Okayasu I. CD44 expression in normal, hyperplastic, and 438 malignant endometrium. J Pathol 1998;184:297-306.

439 Saegusa M, Okayasu I. Up-regulation of CD44 variant exon expression in endometrial 440 carcinomas: analysis of mRNA and protein isoforms, and relation to 441 clinicopathological factors. Jpn J Cancer Res 1998;89:291-298.

442 Schmits R, Filmus J, Gerwin N, Senaldi G, Kiefer F, Kundig T, Wakeham A, Shahinian 443 A, Catzavelos C, Rak J et al. CD44 regulates hematopoietic progenitor distribution, 444 granuloma formation, and tumorigenicity. Blood 1997;90:2217-2233.

445 Senbanjo LT, Chellaiah MA. CD44: A Multifunctional Cell Surface Adhesion Receptor 446 Is a Regulator of Progression and Metastasis of Cancer Cells. Front Cell Dev Biol $447 \quad 2017 ; 5: 18$.

448 Simon A, Safran A, Revel A, Aizenman E, Reubinoff B, Porat-Katz A, Lewin A, Laufter $449 \mathrm{~N}$. Hyaluronic acid can successfully replace albumin as the sole macromolecule in a 450 human embryo transfer medium. Fertil Steril 2003;79:1434-1438.

451 Singh H, Aplin JD. Endometrial apical glycoproteomic analysis reveals roles for 452 cadherin 6, desmoglein-2 and plexin b2 in epithelial integrity. Mol Hum Reprod $453 \quad 2015 ; 21: 81-94$. 
454 Singh N, Gupta M, Kriplani A, Vanamail P. Role of Embryo Glue as a transfer medium 455 in the outcome of fresh non-donor in-vitro fertilization cycles. J Hum Reprod Sci $456 \quad 2015 ; 8: 214-217$.

457 Singh H, Nardo L, Kimber SJ, Aplin JD. Early stages of implantation as revealed by an 458 in vitro model. Reproduction 2010;139:905-914.

459 Teklenburg G, Salker M, Heijnen C, Macklon NS, Brosens JJ. The molecular basis of 460 recurrent pregnancy loss: impaired natural embryo selection. Mol Hum Reprod $4612010 ; 16: 886-895$.

462 Teramoto H, Castellone MD, Malek RL, Letwin N, Frank B, Gutkind JS, Lee NH. 463 Autocrine activation of an osteopontin-CD44-Rac pathway enhances invasion and 464 transformation by H-RasV12. Oncogene 2005;24:489-501.

465 Toole BP. Hyaluronan-CD44 interactions in cancer: paradoxes and possibilities. Clin 466 Cancer Res 2009;15:7462-7468.

467 Urman B, Yakin K, Ata B, Isiklar A, Balaban B. Effect of hyaluronan-enriched transfer 468 medium on implantation and pregnancy rates after day 3 and day 5 embryo transfers: 469 a prospective randomized study. Fertil Steril 2008;90:604-12.

470 Zheng Q, Zhang D, Yang YU, Cui X, Sun J, Liang C, Qin H, Yang X, Liu S, Yan Q. 471 MicroRNA-200c impairs uterine receptivity formation by targeting FUT4 and alpha1,3472 fucosylation. Cell Death Differ 2017;24:2161-2172.

\section{Figure legends}

474 Figure 1 CD44 in embryos and Ishikawa cells. A, B. An E4.5 mouse blastocyst 475 fixed in PFA and stained for CD44 using polyclonal antibody H-300 (green). The 
476 embryo is represented using a single Z-plane of the Z-stack together with a X-Z plane 477 image below the blue line from the point indicated by the arrow $(A)$ or in 3D (B). C.

478 Rabbit serum IgG is a negative control. Blue: cell nuclei (DAPI). 5 embryos were 479 stained in 2 batches. D, E. Representative fluorescence images of localisation of 480 CD44 (green) at Ishikawa cell lateral membranes using monoclonal antibody $5 \mathrm{H} 12$ in 481 the mid-plane (D) or apical plane (E). The actin cytoskeleton is red (Alexafluor 594482 phalloidin). The $X-Z$ plane (bottom of image) reveals CD44-positive epithelium. $N=3$.

483 F. Negative control (anti-KLH monoclonal with rhodamine-phalloidin and DAPI). Scale $484 \operatorname{bar}(B, C, F)=20 \mu m$.

485 Figure 2 CD44 in embryo-epithelial attachment sites. Mouse embryos attached 486 after $48 \mathrm{hrs}$ co-culture with Ishikawa cells were fixed and stained with antibody $5 \mathrm{H} 12$ 487 (green), which detects human but not mouse CD44. A. The main image shows 488 confluent unbreached epithelial cells. An attached embryo is centred at the position of 489 the asterisk. The $X-Z$ plane (bottom of image) collected on the line of the arrow 490 reveals trophoblast (arrow) attached to CD44-positive epithelium. B. A later stage in 491 which trophoblast has displaced epithelial cells. The area lacking green staining at 492 centre reveals the position of the embryo. A blue arrow again indicates the location of 493 the X-Z section shown at bottom, with white arrows indicating the embryonic periphery 494 where trophoblast and displaced epithelium are in apposition. C. Still later, with 495 prominent actin bundles (arrows in top left image) characteristic of trophoblast giant 496 cells in the plane of the substrate. The position of the embryo is also revealed by the

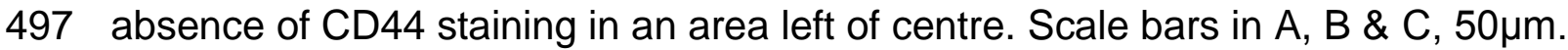

498 Figure 3 Characterisation of impact of anti-CD44 antibody on embryo 499 attachment and stability. A, B. Ishikawa cell spreading assay in which trypsinised 
500 cells were plated on the indicated substrates and incubated for $1 \mathrm{hr}$. Spreading was

501 scored with the aid of a phase contrast microscope. Control cells spread on culture 502 plastic, poly-lysine, or osteopontin. The anti-CD44 polyclonal antibody H300 effects 503 partial inhibition of spreading on osteopontin but does not influence behaviour on the 504 other substrates. C, D. Embryo-epithelial attachment assay with H-300 antibody 505 added just prior to co-culture from E4.5. Three conditions, control (no antibody), 506 anti-CD44 antibody and control lgG, are respectively represented in blue, red and 507 green. All conditions were analysed for the percentage of embryos attached either 508 weakly, intermediately or stably, and those that had advanced to attach intermediately 509 and stably. E, F. Plots show attachment when antibody was added to detached 510 embryo co-cultures after $24 \mathrm{~h}$. Data are presented as mean \pm SEM and statistical 511 analysis was performed using 2-way ANOVA with Bonferroni's multiple comparison 512 test $\left({ }^{*}: \mathrm{P}<0.05 ;{ }^{* *}: \mathrm{P}<0.01 ;{ }^{* * *}: \mathrm{P}<0.001\right) . \mathrm{N}=4$ (48 embryos per condition).

513 Figure 4 Effect of hyaluronidase treatment on embryo attachment. A. The 514 HA-binding domain of versican (green) was used to reveal $\mathrm{HA}$ at the surface of 515 Ishikawa cell layers. The inset shows staining in the absence of binding protein. B. 516 After treatment with Hyal2, staining is lost. C. Quantification of HA fluorescence. D. 517 CD44 staining (green) before and after Hyal2 treatment of Ishikawa cells. Total green 518 fluorescent pixels above background before and after treatment, showing no

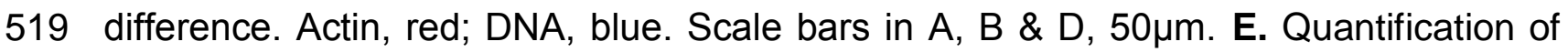
520 CD44 fluorescence. F. Mouse embryo total attachment from E5.5-6.5 under four 521 conditions of Hyal2 treatment of: embryos (red), Ishikawa cells (green), both (purple) 522 or neither (blue). G. Mouse embryo stable attachment plotted. Data are presented as 523 mean \pm SEM and statistical analysis was performed using 2-way ANOVA with 
524 Bonferroni's multiple comparison test (*: $\left.\mathrm{P}<0.05 ;{ }^{* *}: \mathrm{P}<0.01 ;{ }^{* \star *}: \mathrm{P}<0.001\right) . \mathrm{N}=4$ (48

525 embryos per condition). Scale bar (A, B, D) $=50 \mu m$ 
Figure 1
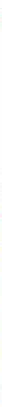


\section{Figure 3}

A

B

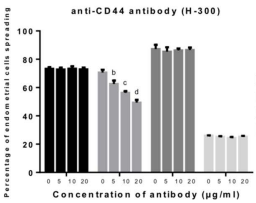

Control SF

OPN $5 \mu \mathrm{g} / \mathrm{mL}$

PolyL-lysine $5 \mu \mathrm{g} / \mathrm{mL}$

BSA $5 \mu \mathrm{g} / \mathrm{mL}$

C

D
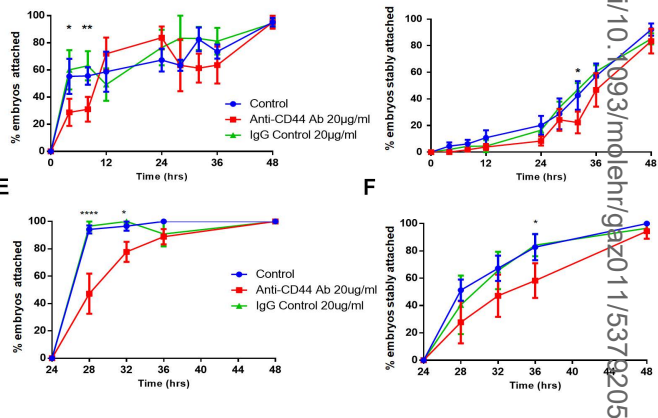
Figure 4
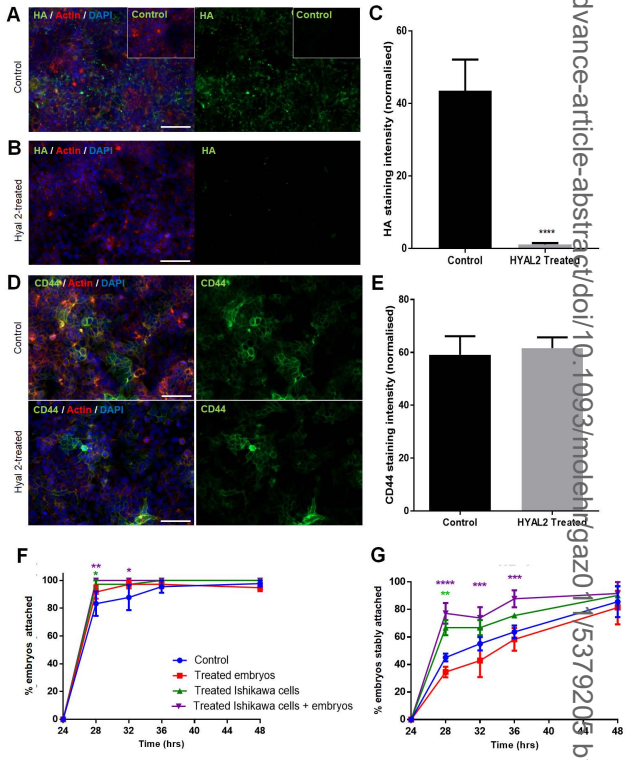